\title{
HISTORY OF MEDICINE Heart transplantation: Research that led to the first human transplant in 1967
}

\author{
J Hassoulas
}

The first experimental heart transplantation was performed by Demikhov in Moscow in the very early 1940s. His experiments were discontinued during World War II but, when they resumed in 1946, he produced a large volume of work devising 24 different methods of heterotopic heart transplantation within the chest. During the 1950s, many research workers transplanted the heart in the orthotopic position and also transplanted the heart and lungs en bloc. They used various methods, including cardiopulmonary bypass (heartlung machine). During the 1960s, Lower and Shumway established beyond doubt that heart transplantation was a possibility. Christiaan Barnard, using their surgical techniques, performed the first humanto-human heart transplant, in December 1967 in Cape Town.

\section{Early transplantation attempts $\mathbf{s}^{1,2}$}

The possibility of replacing diseased tissues and organs with healthy ones from the same or other species has interested man since ancient times. In the Iliad, Homer mentions a monster called the Chimera that possessed the characteristics of various animals, e.g. a lion's body with wings. There are references throughout Greek mythology to mythical humans possessing one or more animal limbs.

About 2000 years ago in India, rhinoplasty and similar operations for the repair of various facial defects were performed by using local skin flaps, i.e. autologous skin transplants. These operations were described by Celsus in Graeco-Roman medical literature, and it seems that they were also performed in Greece and Rome. Fifteenth-century Italian surgeons also devised pedicle flaps for plastic procedures but, owing to church interference in medical matters, this technique had to be abandoned. Much later, English army doctors stationed in India rediscovered procedures for plastic operations on the nose and introduced them in England.

Apart from the successful transplantation of autologous skin, no transplantation of any tissues or organs seems likely to have taken place until about a century ago. There is evidence that successful skin transplants on sheep were performed in Milan in the 18th century, and it was claimed that these skin allografts (homografts) were successful. This might have been possible if the animals were from the same region and could therefore be genetically related, but those researchers went on to claim that xenografts took as well, and ascribed this fact to the 'good air that prevails in Milan', which casts serious doubt on the validity of these experiments. Paul Bert, a student of Claude Bernard and an early worker on transplantation research, wrote a thesis and later produced about 200 publications on the subject of animal tissue grafting. Except for autografting of the skin, he was unable to reproduce the Milanese claims. Bert's works were published in 1876 and were translated into English in 1943.

Dr J Hassoulas, MB ChB, MMed (Thor Surg), MD, is an associate professor at the Medical School, University of Crete, Greece.
He noted the behaviour of autografts, allografts and xenografts, and believed allografts could have a successful outcome.

Corneal transplants were carried out as far back as 1872 using xenografts, but were unsuccessful. Allograft corneal grafts, however, were the first successful tissues to be transplanted, the earliest being around 1930.

Organ transplantation was first attempted in the early 20th century. Previously, Murphy and Beck had devised vascular suturing methods, and these were used by Carrel in transplanting organs. Carrel observed that kidneys transplanted from one site to another in the same animal had a better survival rate than those from other animals. He believed, however, that the functioning of the transplanted organ depends on the success of the vascular anastomosis. This thinking persisted until the 1940s, with many researchers spending all their time and effort devising better and faster techniques for the anastomoses of vessels.

Some human application of these techniques was attempted. Ullman, in 1902, having experimented with kidney allograft transplantation in dogs, transplanted a pig's kidney into the elbow of a uraemic woman. The kidney did not function and he thought this was due to technical problems. At that time, many other research workers reported experimental kidney transplantation, some of whom also attempted transplantation from animals to man. The overall experience was reviewed by Guthrie in 1912, who summed up the situation as follows: 'No one, though many experiments have been reported, has yet succeeded in keeping an animal alive for any great length of time which carried the kidney or kidneys of another animal, after its own kidneys were removed ... the outlook is by no means hopeless and the principle of immunity which yields such brilliant results in many other fields would be worthy of being tested in this case. ${ }^{1}$

\section{Blood groups and transfusions $\mathbf{s}^{3,4}$}

Blood grouping and blood transfusions are an integral part of transplantation. Ancient Greek and Egyptian writings show that, even in those early times, blood transfusions were held to be both advisable and indeed possible. The first recorded attempt to use blood for therapeutic purposes was in 1492. However, in this instance, Pope Innocent VIII was probably given blood orally. Following the discovery of the circulation of blood by Harvey in 1616, several further experiments paved the way for the first transfusion. In 1656, the famous English architect Sir Christopher Wren administered beer and wine intravenously to dogs, resulting in their intoxication and thereby proving that substances can be given intravenously. In 1665, another Englishman, Lower, transfused blood from one dog into another. In 1667, a Frenchman, Denis, performed the first blood transfusion by transfusing lamb's blood into a human recipient. Using calf's blood for his fourth blood transfusion, and the second blood transfusion for the recipient concerned, a fatal haemolytic reaction followed. Denis was tried for manslaughter and, although acquitted, transfusions were banned in Paris, London and Rome, and no further advances in this field were recorded for 150 years. Eventually, the first human-to-human blood transfusion was successfully performed in 1818 by Bundell, an English obstetrician. Interest in transfusion therapy thereby revived, but this was not used on a large scale owing to the frequent and often fatal reactions that resulted. 
In 1900 and 1901, Landsteiner published his discovery of the $\mathrm{ABO}$ blood group system. This important discovery was not clinically applied until 1911. Discoveries such as the use of citrate as an anticoagulant in 1914, and later the addition of dextrose to the anticoagulant solution, increased the lifespan of the red blood cells in vitro. The Rh system was discovered in 1940 by Landsteiner and Wiener. During World War II, blood transfusions were commonly performed. Following this experience, blood banks were established worldwide and blood transfusion became a safe and everyday procedure.

\section{Historical aspects of cardiac surgery}

Direct surgery on the heart is a comparatively recent event. Between 1810 and 1824, the great military surgeon Larrey ${ }^{5}$ drained the pericardial sac successfully. He noted the pressure effects created by blood-stained pericardial effusions sustained in war wounds. Block ${ }^{6}$ in 1882 showed that a rabbit's heart could be sutured with success. In $1897, \mathrm{Rehn}^{7}$ successfully sutured a stab wound to the heart of a man. The famous surgeon Stephen Paget asserted in 1896 that 'the surgery of the heart has probably reached the limits set by nature to all surgery'.

Brunton $^{8}$ wrote in 1902 of the possibility that mitral valve stenosis might be treated surgically. $\mathrm{He}$ and others stimulated the notion that surgery on the heart is possible, yet others strongly criticised such ideas. Experimental activity followed, and this knowledge was later applied clinically in the surgical treatment of mitral stenosis. The results were very poor, however, with almost all patients dying during the procedure. Two patients who managed to survive were probably not much relieved of their symptoms. In retrospect, the development of the valvulotome, devised by Cutler to cut the mitral valve open, has been blamed as something that kept cardiac surgery back for 20 years.

In 1925, Soutar, for the first and only time in his life, felt the mitral valve through the left atrial appendage and saw the possibilities of mitral valvotomy by this approach. It was, however, only after 1948 that Baily, Brock and Harken ${ }^{9}$ successfully performed a considerable amount of mitral valvotomies and showed that the best approach is through the left atrial appendage. Considerable contribution to this success came through developments in anaesthesia, tracheal intubation, mechanical ventilation and advances in the design of surgical clamps by Potts, DeBakey, Cooley and others. These innovations placed cardiac surgery on a sound foundation. ${ }^{2}$

The following years saw the spectacular development and perfection of pump-oxygenators, heart valves and techniques that have made cardiac surgery an everyday procedure that can be offered to all, with a mortality and morbidity equal to or lower than other forms of major surgery.

\section{Early experimental orthotopic heart transplantation and heart and lung transplantation}

In 1953, Neptune et al..$^{10}$ were the first to attempt complete orthotopic transplantation of the heart and lungs in canine experiments, using moderate profound hypothermia with circulatory arrest for periods up to 30 minutes. The superior vena cava and aorta were rapidly sutured first; the donor trachea was intubated and ventilated, and partial circulation resumed. Finally, the inferior vena cava was sutured over polythene tubing, thereby completely restoring circulation. Heparin was not used. They relied upon decreased coagulability at low temperatures. Three such transplants were reported, with survival up to 6 hours. The transplanted heart maintained the full circulation and, upon restoration of body temperature to normal, reflexes and spontaneous respiration returned. Similar heart and lung transplants were performed by Sen et al..$^{11,12}$ in India, using deep hypothermia and circulatory arrest. The basic principles of this method were established.

Orthotopic isolated transplantation of the canine heart was first performed by Goldberg et $a l^{13}$ in 1958. With the use of cardiopulmonary bypass, 3 orthotopic transplants were performed where the transplanted heart sustained the circulation for periods from 20 minutes to 2 hours after discontinuation of bypass. In the same year, Blanco et al. ${ }^{14}$ used cardiopulmonary bypass in transplanting the heart and lungs. The transplantation of both organs was done for technical reasons, to minimise the number of anastomoses necessary. Function of the transplanted viscera was documented for up to $4 \frac{1}{2}$ hours after completion of surgery.

In a series of heart transplants, heart and bilateral lung transplants, and heart and one lung transplants in 1957, Webb and Howard ${ }^{15}$ concluded that the latter would circumvent respiratory paralysis by leaving one innervated lung in the recipient. The same authors, together with Neely, ${ }^{16}$ in 1959 reported further experimental work in the transplantation of the heart with the right lung. Their experience with autotransplants of the heart and lungs demonstrated that if the trachea is sectioned at the carina so as to leave a well-innervated trachea, spontaneous return of respiration is possible.

\section{Experimental heterotopic heart transplantation within the chest}

The transplantation of the canine heart as an additional heart within the chest was first performed by Demikhov in $1946 .{ }^{17}$ This experience, together with that of experimental transplantation of many vital organs, is presented in a book published in 1962. The original text in Russian was published in 1960. His first attempts at heart transplantation started in 1940, when he transplanted the heart in the inguinal region of cats. During World War II, the experiments were discontinued. Demikhov resumed experimental transplantation of the heart in 1946, subsequently devising 24 different methods for transplanting an additional heart in the chest. In most of these methods, a part of the donor's lung was also transplanted; 250 such experiments were performed over a period of 14 years. Many animals died during surgery as a result of bleeding or technical problems. Most died a few days after surgery from infections, haemorrhage, pneumothorax and other complications. A few animals survived to a couple of weeks or more, and one survived for 32 days.

Since these experiments were done without the aid of cardiopulmonary bypass, the lengths of the various vessels of the donor heart had to be long to reach the vessels to be sutured to the recipient. Suture-line complications were the most frequent problem. Many variations of anastomosing these vessels were used, from direct suture to the use of collodion tubes over which the vessel was sutured. Use was made of a vascular suturing machine devised by Russian engineers and surgeons. Many anastomoses eroded through and many others clotted up, resulting in the rapid death of the animals. Infection was a major problem as antibiotics were not used.

However, many animals survived and observations were recorded. The peripheral pulse was double. The electrocardiograms taken showed the 2 different QRS-complexes of the 2 hearts, similar to today's human heterotopic heart transplants. Electrocardiograms done over days and weeks showed a gradual decrease in donor heart voltage and eventual ventricular fibrillation. However, Demikhov did not relate this to rejection of the graft. Although mentioning incompatibility of tissues and other physiological causes for the death of the transplanted organs, he considered the major reason to be mechanical, within the myocardium, or due to causes around it, e.g. 


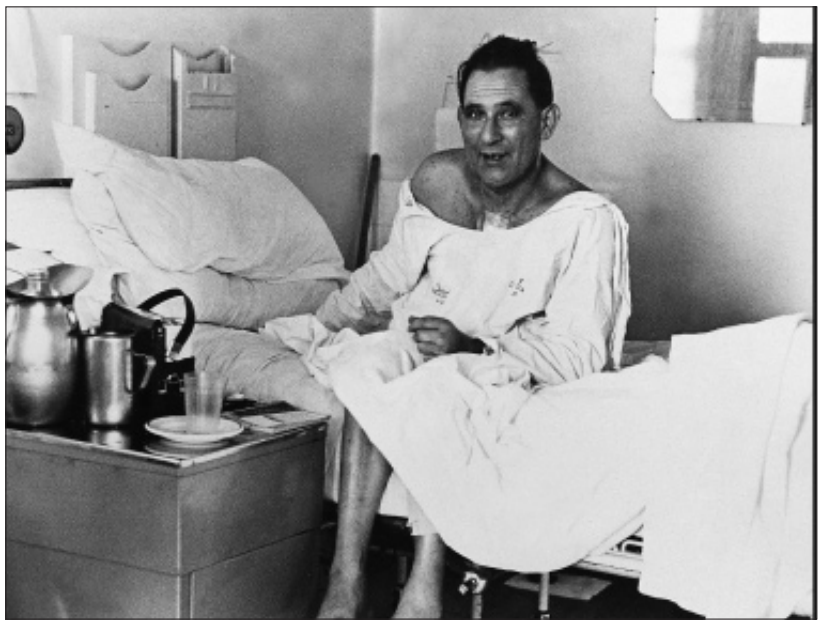

Fig. 1. Louis Washkansky, the first human-to-human heart transplant patient on 3 December 1967, seen here a few days after the operation. (Photo from the Heart of Cape Town Museum.)

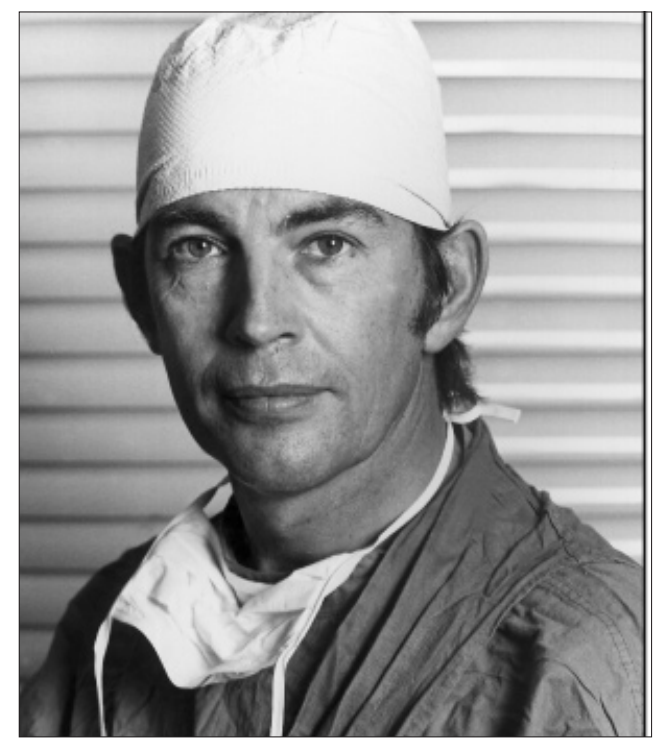

Fig. 2. Christiaan Barnard.

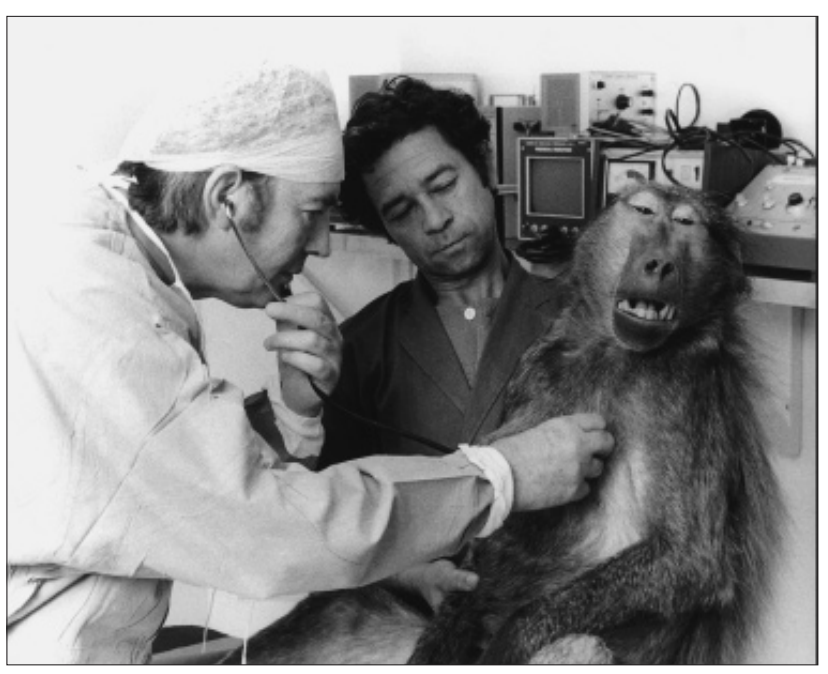

Fig. 3. Professor Barnard at the animal research laboratory, University of Cape Town.

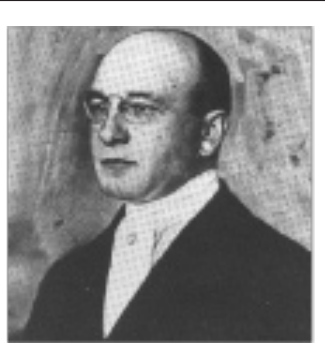

Alexis Carrel
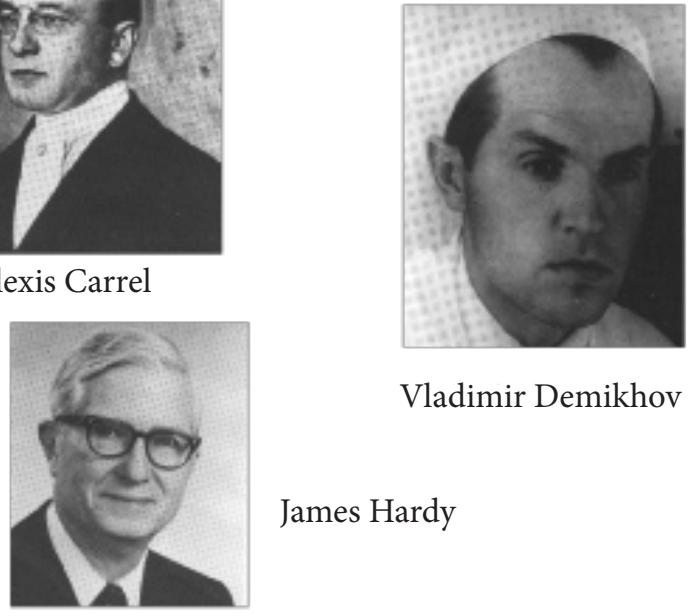

Vladimir Demikhov

James Hardy

Fig. 4. Three of the earlier transplant pioneers.

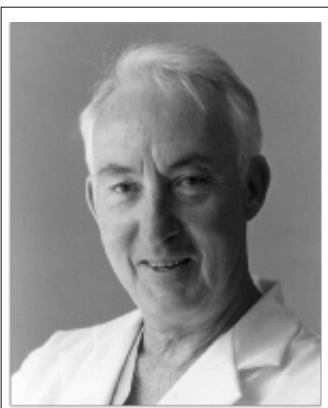

1 Norman Shumway

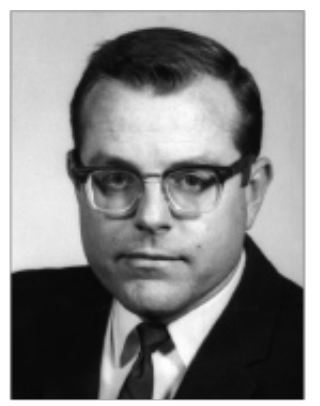

Richard Lower

Fig. 5. The main research workers in heart transplantation in the 1960 s.

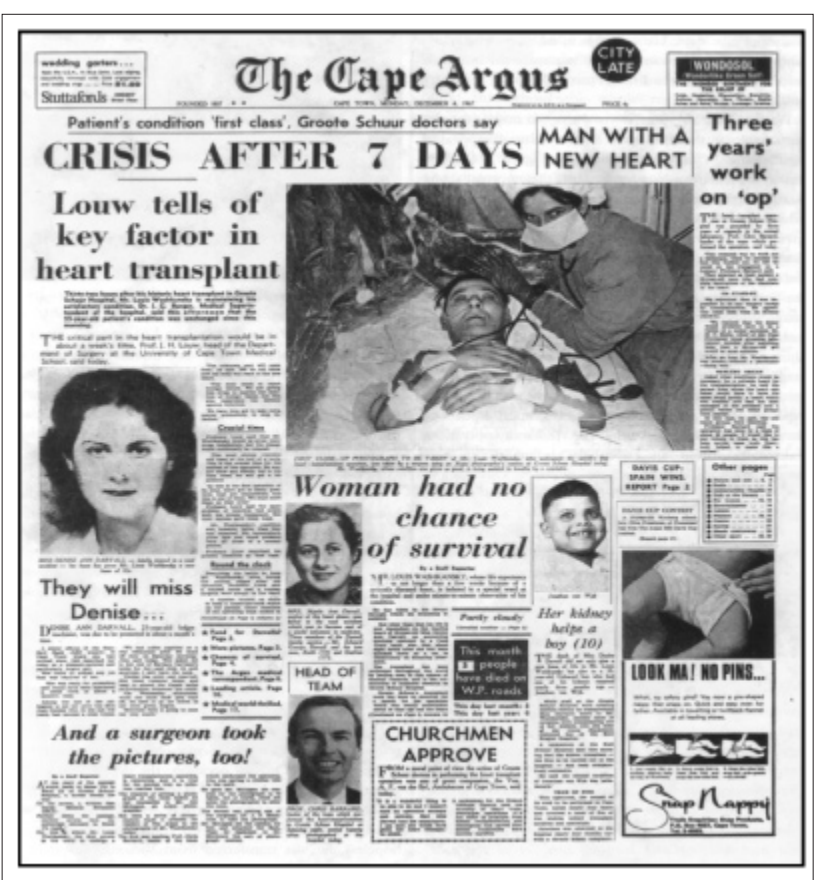

Fig. 6. Local newspaper coverage of the historical event. (Photo from the Heart of Cape Town Museum.) 
pericardial effusion. Professor Christiaan Barnard visited Demikhov in Moscow. In his book One Life, ${ }^{18}$ he mentions that he visited the Soviet Union after his return from Minneapolis in the early 1960s and that he presented a paper at a conference in Moscow at the time.

Sen et al., ${ }^{11}$ in a preliminary 1965 report of 100 canine heart transplant experiments, included 5 experiments performed in which the donor heart supported the circulation as an accessory heart in the chest. The technique used was that the aorta and pulmonary artery of the donor heart were sutured end-to-side on the recipient's descending thoracic aorta and pulmonary artery. The left atrial appendage of the donor heart was sutured to the left atrial appendage of the recipient heart. Only in 3 experiments did the heart start beating after surgery and continue to beat for 6,8 and 48 hours respectively. From this limited experience, the authors formed no opinion other than to suggest further studies.

Reemtsma, ${ }^{19}$ (in 1964) and McGough, Brewer and Reemtsma ${ }^{20}$ (in 1966) described a technique for the insertion of an intrathoracic auxiliary heart, functioning in parallel with the recipient heart.

\section{Experimental orthotopic heart transplantation in the $1960 \mathrm{~s}$}

During this decade, the feasibility of heart transplantation was established beyond doubt. Lower and Shumway and associates emerged as the main researchers in this new and promising field. The first series of completely successful heart transplants was reported by Lower and Shumway in $1960 .^{21}$ The canine heart was transplanted orthotopically using a technique devised by them, whereby a cuff of both atria is left behind in the recipient's chest and the donor atria are sutured onto these cuffs. The other two anastomoses are the aorta and the pulmonary artery. This was performed using cardio-pulmonary bypass. Five out of a series of 8 animals survived the operation, living between 5 and 21 days. The postoperative convalescence was uncomplicated and the animals returned to normal activity. Postmortem histological examination of the heart revealed severe acute rejection, with massive round cell infiltration, patchy necrosis, interstitial haemorrhage and oedema. These observations confirmed that the immunological mechanism of the host attacks the heart and that this leads to rapid myocardial failure.

In 1961, Lower, Stofer and Shumway ${ }^{22}$ published a more detailed article on their experimentation with orthotopic heart transplantation. Obtaining and preserving the graft in a viable state was a problem they gave attention to, resorting to refrigeration in cold saline to diminish the heart's metabolic requirements during the anoxic period. The surgery for removing the donor heart and the transplantation techniques are discussed. Significant progress included using the posterior walls of the atria of the recipient, obviating the need for multiple anastomoses of the cavae and pulmonary veins. Serial electrocardiograms obtained on surviving animals showed gradual decrease in voltage. Histological analysis confirmed the process of homograft rejection.

Heart and lung transplantation was also attempted by Lower et al..$^{23}$ in 1961. In 6 experiments, 4 animals died within 24 hours of surgery, and 2 survived for 5 days. The postoperative respiration rate of the animals was decreased and the respiration pattern was altered.

By the mid-1960s, considerable information had been obtained on many aspects of heart transplantation, such as the development of an uncomplicated surgical technique, preservation of the myocardium during interruption of coronary blood flow, adequate function of the anatomically denervated transplanted heart postoperatively, and the diagnosis and treatment of acute rejection. This provided the scientific foundation upon which clinical heart transplantation commenced.
The first human-to-human heart transplant was performed on 3 December 1967 in Cape Town by Professor Christiaan Barnard. This historical event opened a new and exciting chapter in medical science. Media coverage evoked much mixed and even heated reaction at times regarding the question of ethics in organ transplantation. ${ }^{24}$ Due to varying enthusiasm and sensationalism, an inaccurate picture of the facts was given, presenting transplantation to the lay public as both a panacea and also an unjustified, unethical form of treatment. ${ }^{24}$ The medical profession responded with mixed feelings: some believed that this form of therapy was unjustifiable and unethical, ${ }^{24}$ while others responded with tremendous enthusiasm, which was reflected by the fact that over 100 heart transplants were performed in various centres around the world in the next year (1968).

The rather poor results following this experience, however, had a negative effect on the initial enthusiasm for heart transplantation. Only a few institutions maintained active heart transplant programmes, including the University of Cape Town. Professor Barnard ${ }^{24}$ stated in 1970: 'To curb transplantation at this stage would be to strangle one of the most promising and exciting fronts of medical endeavour of this century. From the experience gained in the problems of rejection, methods of immunological control will be improved and vital organ replacement will become a routine and life-saving procedure. To deny medicine its full thrust in this direction would be irresponsibly shortsighted. Indeed, it is difficult not to conclude that any withdrawal from this new frontier would be professionally unethical. We have only to continue transplantation on a most active scale.'

Worldwide, 101 heart transplants were performed in 1968, 47 in 1969 and, since then, an average of about 25 annually. By July 1977, 345 heart transplants had been performed by 65 transplant teams in 22 countries on 337 recipients. During the 1980s, worldwide interest in this procedure was renewed, owing to the fact that the therapeutic value of heart transplantation had been proven. During 1981, more than 100 heart transplants were again performed. It was estimated that at least 666 heart transplants had been performed worldwide by March 1982.

The registry of the International Society for Heart and Lung Transplantation: Twenty-third Official Adult Heart Transplantation Report - 2006, presents information on the 73000 heart transplants performed worldwide from 1982 to $2005 .^{25}$ The one-year survival was reported to be about $80 \%$ and 5-year survival $70 \%$. Careful patient selection, together with vigorous postoperative management, today ensures the satisfactory rehabilitation of selected heart disease patients who would otherwise die. Future improvements in methods of immunosuppression and the refinement of prolonged myocardial preservation techniques ${ }^{26,27}$ will greatly extend the horizon of heart transplantation in the near future.

Currently, about 3000 heart transplants are performed annually worldwide. However, in the USA alone, there is a need for assistance to the heart in more than 70000 patients annually who are in terminal heart failure. They need more help than maximal medical therapy. Consequently, human-to-human heart transplantation still has very little impact on the treatment of end-stage heart failure. Therefore, an intensive search for improved, permanent mechanical devices as alternatives to heart transplantation has to continue 'on a most active scale.24

\footnotetext{
Rapaport FT, Dauset J. Human Transplantation. New York: Grune \& Stratton, 1968: 3. Davis L. Christopher's Textbook of Surgery 9th ed. Philadelphia: WB Saunders, 1969: 1424 2. Davis L. Christopher's Textbook of Surgery. 9th ed. Philadelphia: WB S Malut NSR. History of blood transfusions. J Hist Med 1955;9:59-107.
Sturgis CC. Hematology. 2nd ed. Springfield, Ill: Charles C Thomas, 1955

5. Norman JC. Cardiac Surgery. 2nd ed. New York: Appleton-Century-Crofts, 1972:671-67

6. Block MH. Uber Wunden des Herzen und des Herzbentelf. Verh Deutsch Ges Chir 1882;11:108.
} 
7. Rehn. Ueber penetrirende Herzwunden und Herzhalt. Arch Klin Chir 1897;55:315

8. Brunton TL. Possibility of treating mitral valve stenosis by surgical methods. Lancet 1902;1: 352 .

Ellis HF. Surgery for acquired mitral valve disease. Philadelphia, USA: WB Saunders, 1967: 15-17.

10. Neptune WB, Cookson BA, Bailey CP. Complete homologous heart transplantation. Arch Surg (Chicago) 1953;66:174

1. Sen PK, Parulkar GB, Pandy SR, Kinare SG. Homologous canine heart transplantation: A preliminary report of 100 experiments. India J Med Res 1965;53:67

2. Sen PK, Shah CB, Satoskar RS. Studies on isolated heart lung preparations in the hypothermic animal. J Internat Coll Surgeons 1956;26:32.

3. Goldberg M, Berman EF, Akman RC. Homologous transplantation of the canine heart. J Internat Coll Surgeons 1958;30:575

14. Blanco G, Adam A, Rodriques-Perez D, Fernandes A. Complete homotransplantations of the canine heart and lungs. Arch Surg (Chicago) 1958;76:20.

15. Webb WR, Howard HS. Cardiopulmonary transplantation. Surgical Forum 1957;8:313.

16. Webb WR, Howard HS, Neely WA. Practical methods of homologous cardiac transplantation. J Thoracic Surg 1959;37:361.

17. Demikhov VP. Experimental Transplantation of Vital Organs. New York: Consultants Bureau, 1962: 54.

18. Barnard C, Pepper CB. Christiaan Barnard: One Life. Toronto: MacMillan, 1969.

18. Barnard C, Pepper CB. Christiaan Barnard: One Life. Toronto: MacMillan, 1969 .

19. Reemtsma K. The heart as a test organ in transplantation studies. Ann N Y Acad Sci 1964;120:778.
20. McGough EC, Brewer PL, Reemtsma K. The parallel heart: Studies of intra-thoracic auxiliary cardia McGough $\mathrm{CC}$, Brower PL, Reem
21. Lower RR, Shumway NE. Studies on orthotopic transplantation of the canine heart. Surg Forum 1960;11:18.

2. Lower RR, Stofer RC, Shumway NE. Homovital transplantation of the heart. J Thorac Cardiovasc Sur 1961;41:196.

23. Lower RR, Stofer RC, Hurley EJ, Shumway NE. Complete homograft replacement of the heart and both lungs. Surgery 1961;50:842.

4. Barnard CN. Experience with human heart transplantation in "Sterilization and preservation of biological tissues by ionizing radiation". Vienna: International Atomic Energy Agency, 1970. IAEA PL - 333/10:79-94.

25. Twenty-third Official Adult Heart Transplantation Report - 2006. J Heart Lung Transplant 2006;25:869-

26. Wicomb W, Cooper DK, Hassoulas J, et al: Orthotopic transplantation of the baboon heart after 20 to 24 hours' preservation by continuous hypothermic perfusion with an oxygenated hyperosmolar solution. Thorac Cardiovasc Surg 1982;83:133-140

27. Hassoulas J, Barnard CN. Heterotopic cardiac transplantation. A 7-year experience at Groote Schuur Hospital, Cape Town. S Afr Med J 1984;65(17):675-682.

Accepted 16 July 2010 